This is an electronic reprint of the original article. This reprint may differ from the original in pagination and typographic detail.

Author(s): Ghalibaf, Maryam; Lehto, Joni; Alén, Raimo

Title: $\quad$ Fast pyrolysis of hot-water-extracted and delignified silver birch (Betula pendula) sawdust by Py-GC/MS

Year: $\quad 2017$

Version:

Please cite the original version:

Ghalibaf, M., Lehto, J., \& Alén, R. (2017). Fast pyrolysis of hot-water-extracted and delignified silver birch (Betula pendula) sawdust by Py-GC/MS. Journal of Analytical and Applied Pyrolysis, 127, 17-22. https://doi.org/10.1016/j.jaap.2017.09.008

All material supplied via JYX is protected by copyright and other intellectual property rights, and duplication or sale of all or part of any of the repository collections is not permitted, except that material may be duplicated by you for your research use or educational purposes in electronic or print form. You must obtain permission for any other use. Electronic or print copies may not be offered, whether for sale or otherwise to anyone who is not an authorised user. 


\section{Accepted Manuscript}

Title: Fast pyrolysis of hot-water-extracted and delignified silver birch (Betula pendula) sawdust by Py-GC/MS

Authors: Maryam Ghalibaf, Joni Lehto, Raimo Alén

PII: S0165-2370(17)30410-2

DOI: http://dx.doi.org/10.1016/j.jaap.2017.09.008

Reference: JAAP 4135

To appear in:

\section{J. Anal. Appl. Pyrolysis}

Received date:

4-5-2017

Revised date:

Accepted date:

Please cite this article as: Maryam Ghalibaf, Joni Lehto, Raimo Alén, Fast pyrolysis of hot-water-extracted and delignified silver birch (Betula pendula) sawdust by Py-GC/MS, Journal of Analytical and Applied Pyrolysishttp://dx.doi.org/10.1016/j.jaap.2017.09.008

This is a PDF file of an unedited manuscript that has been accepted for publication. As a service to our customers we are providing this early version of the manuscript. The manuscript will undergo copyediting, typesetting, and review of the resulting proof before it is published in its final form. Please note that during the production process errors may be discovered which could affect the content, and all legal disclaimers that apply to the journal pertain. 


\title{
Fast pyrolysis of hot-water-extracted and delignified silver birch (Betula pendula) sawdust by Py-GC/MS
}

\author{
Maryam Ghalibaf*, Joni Lehto, and Raimo Alén
}

Laboratory of Applied Chemistry, Department of Chemistry, University of Jyväskylä, PO Box 35, FI-40014 Jyväskylä, Finland

* Corresponding author. Tel.: +358 440100922.

E-mail address: maryam.m.ghalibaf@jyu.fi (M. Ghalibaf).

\section{HIGHLIGHTS}

- Fast pyrolysis has been applied to various solid residues from hot-water-extracted birch sawdust

- Fast pyrolysis has been utilized in the integrated biorefinery concept of birch wood

- A basis of a rapid characterization method for lignocellulosics has been created

\begin{abstract}
The thermochemical behavior of birch (Betula pendula) sawdust both untreated and after various chemical treatments (hot-water extraction, delignification, and hot-water extraction followed by delignification) was investigated by pyrolysis-gas chromatography-mass spectrometry (PyGC/MS). In each case, major GC-amenable condensable products were classified into several compound groups, and the formation of these monomer-related fragments from feedstock samples with varying mass portions of the structural constituents (cellulose, hemicelluloses, and lignin) were determined at $500{ }^{\circ} \mathrm{C}$ and $700{ }^{\circ} \mathrm{C}$ at hold times of $5 \mathrm{~s}$ and $20 \mathrm{~s}$. The formation of pyrolysis products was shown to be characteristically dependent on feedstock composition as well as on pyrolysis conditions. This kind of approach was of practical importance with respect to efforts not only to develop rapid characterization tools for lignocellulosics, but also to new biorefinery possibilities to produce bio-oils, for example, enriched either with aliphatic or aromatic constituents.
\end{abstract}

Keywords: Pyrolysis-gas chromatography; Silver birch; Hot-water extraction; Soda-AQ delignification; Condensable products

\section{Introduction}


Forest lignocellulosic biomass represents a renewable and sustainable alternative for replacing fossil resources for manufacturing chemicals, energy, and other products [1-4]. In many biorefinery processes, various pretreatment technologies, including mechanical upgrading, heating, or chemical treatment, play an important role [3,5-9]. Therefore, in an integrated forest biorefinery concept, one interesting approach, mainly for recovering valuable carbohydratesderived material, is to apply hot-water extraction ("autohydrolysis") to wood chips or sawdust prior to further processing, such as pulping [8,10-12]. It can be concluded that all these types of fractionation possibilities also offer, for example, a wide range of potential feedstocks for thermochemical conversions [13-15].

Thermochemical conversions of lignocellulosic materials have been investigated under a variety of conditions and from several points of view. These rather unselective techniques result in the formation of gases, condensable liquids (tars), and charcoal, whose relative proportions depend on the chosen treatment method and the specific reaction conditions [3]. For example, fast pyrolysis of lignocellulosics, carried out in the complete or near complete absence of an oxidizing agent with a relative high heating rate and a short reaction time typically at 500-700 ${ }^{\circ} \mathrm{C}$, represents a straightforward method that produces a particularly high yield of liquid biofuels and chemicals $[16,17]$. Furthermore, it has been established that the individual main polymeric wood components, carbohydrates (cellulose and hemicelluloses) and lignin, are showing their characteristic degradation behavior during heating [18-22]; for example, carbohydrates typically form anhydrosugars, furans, and monomeric phenols via dehydration, whereas lignin partially loses its aliphatic side chains and degrades.

In this study, the fast pyrolysis of untreated and hot-water-extracted (HWE) silver birch (Betula pendula) sawdust as well as the soda-anthraquinone(AQ)-delignified pulps originated from these untreated and treated feedstocks was investigated by pyrolysis-gas chromatographymass spectrometry (Py-GC/MS). The main aims were, on the one hand, to clarify the relative performance of these feedstocks during pyrolysis and, on the other hand, to evaluate the suitability of this analytical pyrolysis method as a rapid tool for roughly detecting chemical changes that take place in the feedstocks during applied chemical treatments. For obtaining these targets, the chemical composition of condensable product fractions formed under varying pyrolysis conditions was determined.

\section{Experimental}

\subsection{Raw materials and their analyses}

The untreated $\left(\mathrm{B}_{\mathrm{ref}}\right)$ and $\mathrm{HWE}$ (at $170{ }^{\circ} \mathrm{C}$ for 38 min with a yield of $71.9 \%$ [23]) ( $\left.\mathrm{B}_{\mathrm{HWE}}\right)$ silver birch (Betula pendula) sawdust $(<5 \mathrm{~mm})$ as well as the soda-AQ-cooked pulps of untreated $\left(\mathrm{P}_{\text {ref }}\right)$ and of HWE $\left(\mathrm{P}_{\mathrm{HWE}}\right)$ birch feedstocks were investigated.

The soda-AQ delignification experiments were carried out in a laboratory-scale oil-heated batch digester (CRS Autoclave System 420, CRS Reactor Engineering AB, Stenkullen, Sweden) equipped with $1.25-\mathrm{L}$ rotating stainless-steel autoclaves. The treatment conditions were as follows: alkali $(\mathrm{NaOH})$ charge $18 \%$ based on oven-dried (o.d.) feedstock, AQ charge $0.1 \%$ based on o.d. feedstock, temperature $170{ }^{\circ} \mathrm{C}$, time $90 \mathrm{~min}$, and liquor-to-feedstock ratio $5 \mathrm{~L} / \mathrm{kg}$. At the end of each cook, the autoclaves were removed from the oil bath and cooled rapidly with cold tap water. The spent cooking liquor (black liquor) was then separated from the pulp by pressing it through a nylon-woven fabric bag. The pulp obtained was thoroughly washed with 
water, and the amount of removed organic material was calculated based on charged o.d. feedstock; yields for $\mathrm{P}_{\mathrm{HWE}}$ and $\mathrm{P}_{\text {ref }}$ were $53.5 \%$ and $51.6 \%$, respectively.

For the chemical analyses [24], untreated air-dried and hot-water-treated sawdust samples and pulps were ground with a Retsch SM 100 cutting laboratory mill (Retsch GmbH, Haan, Germany) equipped with a bottom sieve with trapezoidal holes (perforation size $<1.0 \mathrm{~mm}$ ) and stored in plastic bags. Prior to analyses, the moisture content was determined according to TAPPI T264 cm-97 standard in an oven at $105{ }^{\circ} \mathrm{C}$. All analyses were carried out with two parallel samples, and the results were calculated as percentages of the dry sample.

The extractives content of the ground samples (about $1.5 \mathrm{~g}$ ) was determined according to the TAPPI T280 pm-99 standard with acetone in a Soxhlet apparatus (extraction time $4 \mathrm{~h}$ with 6-10 percolations per hour). The extract was concentrated nearly to dryness by vacuum evaporation with a rotary evaporator (Heidolph VV2000, Gemini BV Laboratory, Apeldoorn, Netherlands), and drying was finalized before weighing by means of a gentle nitrogen stream.

The lignin content of the extractives-free ground samples was calculated as the sum of the "acid-insoluble (Klason) lignin" and the "acid-soluble lignin" according to the TAPPI T222 om98, T249 cm-00, and T250 UM standards. The acid-soluble lignin content was determined with a Beckman DU 640 UV/Vis spectrophotometer (Beckman Instruments Inc., Fullerton, CA, USA) at $205 \mathrm{~nm}$ after quantitative dilution of the sulfuric acid hydrolysate until the absorbance $A$ was in the range of $0.3-0.8$. The concentration of the dissolved lignin $c(\mathrm{~g} / \mathrm{L})$ was calculated as

$$
c=A /(a \cdot b)
$$

where $a$ is the absorptivity $(110 \mathrm{~L} /(\mathrm{gcm}))$ [25] and $b$ is the length of the light path $(\mathrm{cm})$.

Acid hydrolysis of the extractives-free ground samples was performed according to the TAPPI T249 cm-00 standard, and the resulting monosaccharides were analyzed as their per(trimethylsilyl)ated derivatives using a gas chromatography (GC) system comprising an HP 5890 Series II Plus GC apparatus (Hewlett Packard Company, Wilmington, NC, USA) equipped with a flame-ionization detector (FID). The silylation was made with a mixture of $99 \% \mathrm{~N}, \mathrm{O}$ bis(trimethylsilyl)trifluoroacetamide (BSTFA, Regis Technologies, Morton Grove, IL, USA) and $1 \%$ trimethylchlorosilane (TMCS, Regies Technologies) in pyridine and the mixture was shaken for $60 \mathrm{~min}$ [26]. Xylitol (Fluka Chemical Corporation, Seeltze, Germany) served as an internal standard (IS). The column was a DP-1701 capillary column $(60 \mathrm{~m}$ x $0.32 \mathrm{~mm}$ with a film thickness of $0.25 \mu \mathrm{m}$; Agilent Technologies, Palo Alto, CA, USA). For each monosaccharide, an IS was calibrated based on a separate run with the corresponding model monosaccharide: arabinose, xylose, galactose, glucose, and mannose (all from Fluka Chemical Corporation, Seeltze, Germany). It was then possible to perform chromatogram peaks identification and obtain the mass-based response factor between each monosaccharide and the corresponding IS.

\subsection{Pyrolysis experiments}

About $0.5 \mathrm{mg}$ of samples were pyrolyzed in a quartz tube $(3.0 \mathrm{~cm} \times 1.0 \mathrm{~mm}$ i.d., between quartz wool) at a heating rate of $20^{\circ} \mathrm{C} / \mathrm{ms}$ using a CDS Pyroprobe 1000 resistively heated coil filament pyrolyzer coupled to an HP 5890 II gas chromatograph (Py-GC, Hewlett Packard Company, Wilmington, NC, USA). The column was a ZB-35HT (Inferno) capillary GC column (30 $\mathrm{m} \times 0.25 \mathrm{~mm}$ with a film thickness of $0.25 \mu \mathrm{m}$ ). Detection was carried out with an HP 5970 mass spectrometric detector under electron ionization $(70 \mathrm{eV})$ with $2.92 \mathrm{scan} / \mathrm{s}$ in the $30-550 \mathrm{~m} / \mathrm{z}$ 
interval. For the identification of chromatogram peaks, the mass spectra (based on the National Institute of Standards and Technology (NIST) mass spectral library) were used.

The pyrolysis temperatures were $500{ }^{\circ} \mathrm{C}$ and $700{ }^{\circ} \mathrm{C}$ and in each case, the temperature was kept constant for either $5 \mathrm{~s}$ or $20 \mathrm{~s}$. A splitless capillary injection port was used for the sample feed. The GC oven temperature program in the analyses of pyrolysis products was as follows: 2 min at $40{ }^{\circ} \mathrm{C}, 4{ }^{\circ} \mathrm{C} / \mathrm{min}$ to $190{ }^{\circ} \mathrm{C}, 10{ }^{\circ} \mathrm{C} / \mathrm{min}$ to $320{ }^{\circ} \mathrm{C}$, and $10 \mathrm{~min}$ at $320{ }^{\circ} \mathrm{C}$. Helium was used as carrier gas with a gas flow rate of $1 \mathrm{~mL} / \mathrm{min}$ and as an inert atmosphere in the pyrolysis interface. The Py-GC interface temperature was $250{ }^{\circ} \mathrm{C}$, and the injector temperature was 280 ${ }^{\circ} \mathrm{C}$.

Quantitative analysis was conducted according to other recent studies [27-30] so that pure compounds (the total number was 48) were used as external standards to relatively quantify all the identified peaks from pyrolysis products (Py-GC/MS) by comparing the products to a set of standard samples of known concentration. The chromatogram peak identification was also partly confirmed based on the retention times and mass spectra of these pure compounds. Several standard methanol or acetone solutions in the concentration range of $0.05-8 \mathrm{mg} / \mathrm{mL}$ were prepared, and in all cases, the selected concentrations (five concentrations per each compound) depended on the standard's chromatographic response (GC/MS). The coefficients of determination $\left(\mathrm{r}^{2}\right)$ values of the linear calibration curves were between 0.97-0.99 when a plot of instrument response (peak area, y-axis) vs. concentration of standard solution (in $\mu \mathrm{g}, \mathrm{x}$-axis) was performed. Each response factor represented the slope of the line between the response for a given standard and the origin. Therefore, the relative mass response of a target compound compared to the mass of the corresponding external standard. However, the simultaneous use of all 48 standards was rather complicated in all cases (Table S1 in Supplementary data), and to make this approach more appropriate and less tedious, the standards were classified into five groups (Table S2 and Fig. S1 in Supplementary data) if their relative standard deviation (RSD) of the response factors was less than or equal to $20 \%$ [31]; thus, the slopes of the calibration curves for each standard were agreeably close to one another [28]. These average response factors were then used for the relatively quantitative determination of "similar products" (e.g., either for isomeric compounds or for compounds with similar molecular masses or structures). For example, in this case, the standards 2-methyl-2-cyclopenten-1-one, 4-hydroxy-5-methyl3(2H)-furanone, 3-hydroxy-2-methyl-4H-pyran-4-one, and levoglucosan were, respectively, used for 2-hydroxy-2-cyclopenten-1-one, 3-hydroxy-2-penteno-1,5-lactone, pyran-type compounds, and anhydrosugars.

\section{Results and discussion}

\subsection{Raw materials}

Chemical compositions of the reference initial and differently-treated (i.e., HWE, delignified, and HWE and delignified) birch feedstocks are presented in Table 1. The results indicated that 20-25\% of carbohydrates (mono-, oligo, and polysaccharides) and 30-35\% of the initial lignin were removed by hot-water treatment. This soluble fraction can be utilized for many purposes, and some potential possibilities will be separately investigated in forthcoming studies. The results also suggested that cellulose was rather stable during the treatment, but the loss of xylan, the main hardwood hemicellulose component consisting of xylose moieties, seemed to be 65-70 $\%$. As expected, the typical losses of Klason and acid-soluble lignins were about $25 \%$ and $60 \%$, 
respectively. In practice, due to this treatment, the mass ratio of carbohydrates to lignin in the wood matrix increased from 3.1 to 3.5. In contrast, the corresponding mass ratio of aldohexose units (galactose, glucose, and mannose) to aldopentose units (arabinose and xylose) in the fraction of carbohydrates increased from 2.1 to 6.1 .

\section{TABLE 1}

The chemical composition data on pulps (i.e., $\mathrm{B}_{\text {ref }} \rightarrow \mathrm{P}_{\text {ref }}$ and $\mathrm{B}_{\mathrm{HWE}} \rightarrow \mathrm{P}_{\mathrm{HWE}}$ ) are shown in Table 1. In the former reference case $\left(\mathrm{B}_{\text {ref }} \rightarrow \mathrm{P}_{\text {ref }}\right)$, the total removal of carbohydrates was about $30 \%$ (about $20 \%$ for glucose and about $45 \%$ for xylose), and the degree of delignification was about $95 \%$. The mass ratio of carbohydrates to lignin in the wood matrix clearly increased from 3.1 to 42.9 , but the corresponding mass ratio of aldohexose units to aldopentose units in the fraction of carbohydrates increased only slightly from 2.1 to 2.9. However, in the latter case $\left(\mathrm{B}_{\mathrm{HWE}} \rightarrow \mathrm{P}_{\mathrm{HWE}}\right)$, it was noted that under the same delignification conditions as in case of $\mathrm{B}_{\text {ref }} \rightarrow$ $\mathrm{P}_{\text {ref, }}$ the HWE feedstock was more effectively delignified (about $98 \%$ ) than the corresponding untreated feedstock. Additionally, a higher removal of carbohydrates (about $35 \%$; for glucose, about $30 \%$ and for xylose, about $65 \%$ ) was obtained. The mass ratio of carbohydrates to lignin in the wood matrix significantly increased from 3.5 to 113.7 , and the corresponding mass ratio of aldohexose units to aldopentose units in the fraction of carbohydrates increased from 6.1 to 12.1. The chemical compositions of sulfur-free black liquors formed were not studied here in detail, and the recovery and utilization of the alkali-catalyzed degradation products of carbohydrates (mainly aliphatic carboxylic acids) and lignin in these liquors will be separately studied.

All these chemical treatments carried out according to the principles of integrated biorefinery concepts (i.e., to integrate a hot-water extraction stage to sulfur-free chemical pulping) resulted in various samples, in which the mass ratio of their principal chemical components (cellulose, hemicelluloses, and lignin) varied in a relatively wide range. Therefore, it could be concluded that these lignocellulosic samples were also very suitable as raw material samples for the present pyrolysis investigation.

\subsection{Pyrolysis experiments}

The integrated chromatographic system GC/MS applied was capable of resolving most of the main hydrophilic and lipophilic compounds released from birch samples during pyrolysis, and about 80 compounds were identified. In general, pyrolysis tests under the same conditions led to reproducible results, and a typical pyrogram profile for each sample could be obtained; examples of different samples are given in Figs. 1 and 2. Thus, it could be expected that the total amounts and the relative proportions of varying compounds or compound groups were characteristically dependent on the sample preparation and pyrolysis conditions. This finding was valid, although the total number of pyrolysis products that are normally recovered and identified from laboratory-scale pyrolyzers is known to be low [21].

\section{FIGURE 1}

FIGURE 2 
It is also known that the characteristic feature for all the pyrolysates of lignocellulosics is a prominent amount of fixed gases and volatile products, such as carbon monoxide, carbon dioxide, methanol, acetaldehyde, acetic acid, glycolaldehyde, acetol, and certain $<\mathrm{C}_{5}$ hydrocarbons and/or their derivatives $[18,21]$. In this study, however, only the higher-molarmass condensable products that were formed "rather selectively" from individual constituents were included. For example, acetic acid (a substituent of xylan) is not a relevant indicator of xylan because hot-water extraction and cooking remove it (via acetylation) more than the xylan backbone degrades itself.

For simplicity, the dominant GC-amenable pyrolysis products were classified into several compound groups (Table 2), and the formation of these monomer-related fragments were determined in different cases. It is evident that important contributions of postulated mechanisms for the degradation products in the pyrolysis of wood-derived components have been shown in many investigations [17-21]. Based on these data, it could be roughly concluded that the classes of anhydrosugar, cyclopentenone, furan, lactone, and pyrone derivatives originated from carbohydrates and those of catechol, benzenediol, guaiacol, phenol, and syringol derivatives originated from lignin. The characteristic classes of naphthalene and fatty acid derivatives were obtained from extractives and indene derivatives from xylan, whereas the class of other aromatics (benzene derivatives) was probably formed from all wood constituents.

\section{TABLE 2}

\subsection{Practical considerations}

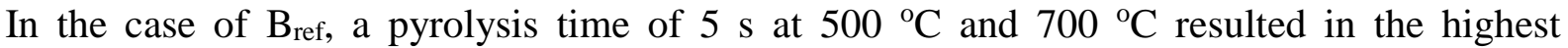
pyrolysis yields similar to those obtained from $\mathrm{B}_{\mathrm{HWE}}$ and $\mathrm{P}_{\text {ref }}$ at $500^{\circ} \mathrm{C}$ for $5 \mathrm{~s}$ (Fig. 3). Typically, the yield was found to decrease or remain almost similar when the pyrolysis temperature increased from $500{ }^{\circ} \mathrm{C}$ to $700{ }^{\circ} \mathrm{C}$. As a general trend, the pyrolysis yields were higher for reference samples (i.e., $\mathrm{B}_{\text {ref }}>\mathrm{B}_{\mathrm{HWE}}$ and $\mathrm{P}_{\text {ref }}>\mathrm{P}_{\mathrm{HWE}}$ ), mainly indicating a higher relative portion of hemicelluloses in these samples (Table 1). The overall treatment yield of samples was 71.9, 51.6, and $38.5 \%$ of the initial $\mathrm{B}_{\text {ref }}$ dry matter for $\mathrm{B}_{\mathrm{HWE}}, \mathrm{P}_{\text {ref, }}$ and $\mathrm{P}_{\mathrm{HWE}}$, respectively. This trend was also reflected in the pyrolysis yields that decreased in order: $\mathrm{B}_{\text {ref }}>\mathrm{B}_{\mathrm{HWE}} \approx \mathrm{P}_{\text {ref }}>\mathrm{P}_{\mathrm{HWE}}$.

\section{FIGURE 3}

The main feedstock chemical constituents degrade on heating at different rates [32]. Under the pyrolysis conditions of this study, varying amounts of carbohydrates- and lignin-derived lowmolar-mass products were formed from these high-molar-mass polymers and could be partly found in pyrolysates. In addition, part of the devolatilized pyrolysis products might be selectively condensed before reaching the GC column. The results, for example, indicated that the formation of lactones from carbohydrates was especially enhanced at $500{ }^{\circ} \mathrm{C}$, and at $700{ }^{\circ} \mathrm{C}$ a slightly more diverse spectrum of products, including compounds, such as indenes, naphthalenes are probably formed from certain cyclic aliphatic extractives, and fatty acids, was detected (Fig. 3). Table 3 shows the ratio aliphatic products to aromatic products obtained in our experiments. As a typical 
trend, more aromatic products were formed under harsher conditions: $700{ }^{\circ} \mathrm{C} / 20 \mathrm{~s}>700{ }^{\circ} \mathrm{C} / 5 \mathrm{~s}>$ $500{ }^{\circ} \mathrm{C} / 20 \mathrm{~s}>500{ }^{\circ} \mathrm{C} / 5 \mathrm{~s}$. Thus, as expected from the sample compositions (Table 1), the maximum portion of aliphatic compounds, 85-95\%, was detected for pulps ( $\mathrm{P}_{\text {ref }}$ and $\left.\mathrm{P}_{\mathrm{HWE}}\right)$ at $500{ }^{\circ} \mathrm{C} / 5 \mathrm{~s}$ and the minimum one, 50-55\%, for delignification feedstocks $\left(\mathrm{B}_{\text {ref }}\right.$ and $\left.\mathrm{B}_{\mathrm{HWE}}\right)$ at 700 ${ }^{\circ} \mathrm{C} / 5 \mathrm{~s}$ and $20 \mathrm{~s}$.

\section{TABLE 3}

It could be roughly considered that the compound groups A, C, F, L, and Y (Table 2) were mainly formed from carbohydrates, $\mathrm{F}$ and $\mathrm{L}$ from xylan, and $\mathrm{G}$ and $\mathrm{S}$ from lignin. Based on this assumption, the ratio carbohydrates to lignin under the pyrolysis conditions studied (Fig. 3) was $2.2\left(\mathrm{~B}_{\mathrm{ref}}\right)$ and $2.3\left(\mathrm{~B}_{\mathrm{HWE}}\right)$ (the corresponding values from the data in Table 1 were 3.1 and 3.5) and, on the other hand, xylan to lignin $1.3\left(\mathrm{~B}_{\text {ref }}\right)$ and $1.4\left(\mathrm{~B}_{\mathrm{HWE}}\right)$ (the value evaluated from the data in Table 1, 0.6-1.1). However, due to many reasons, the straightforward estimation for the ratio carbohydrates to xylan was difficult; an example was the values $1.8\left(\mathrm{P}_{\text {ref }}\right)$ and $2.7\left(\mathrm{P}_{\mathrm{HWE}}\right)$ (from Table 1, about 3.9 and 13.0, respectively).

Since a number of significant pyrolysis products could be measured simultaneously, a single pyrolysis run gave fingerprint data for characterization of feedstock materials. Of the main products, 3-hydroxy-2-penteno-1,5-lactone (I, the compound group L from hemicelluloses), 3methyl-1,2-cyclopentanedione (II, C from hemicelluloses), furfural (III, F from xylan), levoglucosan (IV, A from cellulose), 4-allylsyringone (V, S from syringyl lignin), and isoeugenol (VI, G from guaiacyl lignin) are commonly found in pyrolysates (Table 2 and Fig. 4). It was concluded that a correlation exists between the formation of a number of the products and the chemical composition of feedstock. In this case, for example, at $500{ }^{\circ} \mathrm{C} / 5 \mathrm{~s}$ and $700{ }^{\circ} \mathrm{C} / 5 \mathrm{~s}$ for $\mathrm{B}_{\text {ref }}$ and $\mathrm{B}_{\mathrm{HWE}}$, the $\mathrm{GC}$ peak area ratio (I+II+III+IV)/(V) (i.e., carbohydrates/lignin) was 14.3 and 9.6 (from Table 3.5 and 3.1) and that of (I+II+III+IV)/(V+VI) 5.7 and 3.2, respectively. At 500 ${ }^{\circ} \mathrm{C} / 5 \mathrm{~s}$ for $\mathrm{B}_{\text {ref }}$ and $\mathrm{B}_{\mathrm{HWE}}$, the corresponding ratio (I+III)/(V+VI) (i.e., xylan/lignin) was 4.2 and 6.2 (from Table 1, about 0.6 and 1.1), respectively.

\section{FIGURE 4}

Based on these preliminary results, this fast pyrolysis method seemed to offer a potential tool for feedstock characterization. However, it is evident that for obtaining a good correlation (i.e., the determination of relevant factors) between the pyrolysis and chemical composition data, a wide range of experiments within the same feedstock type is necessary. In this method, practical information was obtained by using the concentration (i.e., GC peak area) ratios of the selected pyrolysis products, thus eliminating the need to measure their absolute concentrations. In contrast, another approach would be to use only a specific single compound for this purpose; however, in this case, to obtain repeatable results, the knowledge about its absolute concentration is required.

\section{Conclusions}

Today, one of the most promising biorefinery techniques is based on hot-water extraction, by which wood chips are treated and partially solubilized prior to sulfur-free alkaline pulping. In 
this study, according to this integrated biorefinery concept, birch sawdust from hot-water extraction and delignification have been pyrolyzed (at $500{ }^{\circ} \mathrm{C}$ and $700{ }^{\circ} \mathrm{C}$ for $5 \mathrm{~s}$ and $20 \mathrm{~s}$ ) to create novel data on condensable low-molar-mass pyrolysis products obtained from these feedstocks and, on the other hand, on possibilities for developing a rapid characterization method for lignocellulosics. In this case, the hydrolysates contained significant amounts of acetic acid, xylose (together with xylose oligomers), and low-molar-mass lignin, which can be utilized in different biorefinery processes.

The composition of feedstock materials as well as pyrolysis conditions have a clear effect on the composition of condensable pyrolysis products, and the characteristic fragmentation patterns for each differently-treated feedstock can be detected. Thus, the effects of the main constituents (cellulose, hemicelluloses, and lignin) in the feedstock materials on the distribution of pyrolysis products are typically seen; lignin-containing materials (untreated and hot-water-extracted sawdust) under harsher pyrolysis conditions result in the pronounced formation of aromatics, whereas aliphatic products can be principally obtained under milder pyrolysis conditions from carbohydrates-containing materials (especially those after delignification).

The pyrolysis experiments also clearly indicate that a simultaneous gas-chromatographic determination of the main low-molar-mass pyrolysis products offers detailed information about the chemical composition of feedstock materials. This finding provides a good basis for further development of a feasible characterization method for lignocellulosics.

\section{Acknowledgements}

Financial support from the Academy of Finland, within the framework of the project IMUSTBC (Maryam Ghalibaf) and from the Maj and Tor Nessling Foundation (Joni Lehto) is gratefully acknowledged. Special thanks are due to Ms. Marja Salo for her skillful assistance with the analytical work. 


\section{References}

[1] B. Kamm, M. Kamm, P.R. Gruber, S. Kromus, Biorefinery systems - An overview, in: B. Kamm, P.R. Gruber, M. Kamm (Eds.), Biorefineries - Industrial Processes and Products, Status Quo and Future Directions, Wiley-VCH Verlag GmbH \& Co. KGaA, Weinheim, 2006, pp. 3-40. [2] M. FitzPatrick, P. Champagne, M.F. Cunningham, R.A. Whitney, A biorefinery processing perspective: Treatment of lignocellulosic materials for the production of value-added products, Bioresour. Technol. 101 (2010) 8915-8922.

[3] R. Alén, Principles of biorefining, in: R. Alén (Ed.), Biorefining of Forest Resources, Paper Engineers' Association/Paperi ja Puu Oy, Helsinki, 2011, pp. 55-114.

[4] A. Pandey, R. Höfer, M. Taherzadeh, K.M. Nampoothiri, C. Larroche (Eds.), Industrial Biorefineries \& White Biotechnology, Elsevier, Amsterdam, 2015.

[5] G. Garrote, H. Domínguez, J.C. Parajó, Mild autohydrolysis: an environmentally friendly technology for xylooligosaccharide production from wood, J. Chem. Technol. Biotechnol. 74 (1999) 1101-1109.

[6] F. Carvalheiro, L.C. Duarte, F.M. Gírio, Hemicellulose biorefineries: a review on biomass pretreatments, J. Sci. Ind. Res. 67 (2008) 849-864.

[7] T.E. Amidon, S. Liu, Water-based woody biorefinery, Biotechnol. Adv. 27 (2009) 542-550.

[8] J. Lehto, Advanced Biorefinery Concepts Integrated to Chemical Pulping, Research Report

No. 180, Doctoral Thesis, University of Jyväskylä, Department of Chemistry, Laboratory of Applied Chemistry, Jyväskylä, Finland, 2015.

[9] H. Rabemanolontsoa, S. Saka, Various pretreatments of lignocellulosics, Bioresour. Technol. 199 (2016) 83-91.

[10] A. van Heiningen, Converting a kraft pulp mill into an integrated forest biorefinery, Pulp Paper Can. 107 (2006) 38-43.

[11] P. Baijpai, Integrated forest biorefinery, in: P. Bajpai (Ed.), Biotechnology for Pulp and Paper Processing, Springer, New York, 2012 pp. 375-402.

[12] R. Alén, Pulp mills and wood-based biorefineries, in: A. Pandey, R. Höfer, M. Taherzadeh, K.M. Nampoothiri, C. Larroche (Eds.), Industrial Biorefineries \& White Biotechnology, Elsevier, Amsterdam, 2015, 91-126.

[13] J. Konttinen, M. Reinikainen, A. Oasmaa, Y. Solantausta, Thermochemical conversion of forest biomass, in: R. Alén (Ed.), Biorefining of Forest Resources, Paper Engineers' Association/Paperi ja Puu Oy, Helsinki, 2011, pp. 262-304.

[14] F.-X. Collard, J. Blin, A review on pyrolysis of biomass constituents: Mechanisms and composition of the products obtained from the conversion of cellulose, hemicelluloses and lignin, Renew. Sustainable Energy Rev. 38 (2014) 594-608.

[15] A. Zhurinsh, G. Dobele, V. Jurkjane, K. Meile, A. Volperts, A. Plavnience, Impact of hot water pretreatment temperature on the pyrolysis of birch wood, J. Anal. Appl. Pyrolysis 124 (2017) 515-522.

[16] D. Radlein, J. Piskorz, D.S. Scott, Fast pyrolysis of natural polysaccharides as a potential industrial process, J. Anal. Appl. Pyrolysis 19 (1991) 41-63.

[17] A.V. Bridgwater (Ed.), Fast pyrolysis of Biomass: A Handbook, Volume 2, CPL Press, Newbury, 2002.

[18] F. Shafizadeh, Pyrolytic reactions and products of biomass, in: P.P. Overend, T.A. Milne, L.G. Mudge (Eds.), Fundamentals and Thermochemical Biomass Conversion, Elsevier, New York, 1985, pp. 183-217. 
[19] R. Alén, E. Kuoppala, P. Oesch, Formation of the main degradation compound groups from wood and its components during pyrolysis, J. Anal. Appl. Pyrolysis 36 (1996) 137-148.

[20] S. Wang, Z. Luo, Pyrolysis of Biomass, Walter de Gruyter GmbH, Berlin/Boston, 2017, pp. 33-140.

[21] V.B.F. Custodis, P. Hemberger, Z. Ma, J.A. van Bokhoven, Mechanism of pyrolysis of lignin: Studying model compounds, J. Phys. Chem. B 118 (2014) 8524-8531.

[22] H. Lappi, Production of Hydrocarbon-rich Biofuels from Extractives-derived Materials, Research Report No. 158, Doctoral Thesis, University of Jyväskylä, Department of Chemistry, Laboratory of Applied Chemistry, Jyväskylä, Finland, 2012.

[23] J. Lehto, R. Alén, Organic materials in black liquors of soda-AQ pulping of hot-waterextracted birch (Betula pendula) sawdust, Holzforschung 69 (2015) 257-264.

[24] C. Chen, R. Alén, J. Lehto, H. Pakkanen, Combustion properties of birch (Betula pendula) black liquors from sulfur-free pulping, J. Wood Chem. Technol. 36 (2016) 401-411.

[25] B. Swan, Isolation of acid-soluble lignin from the Klason lignin determination, Svensk Papperstidn. 68 (1965) 791-795.

[26] R. Alén, K. Niemelä, E. Sjöström, Gas-liquid chromatographic separation of hydroxy monocarboxylic acids and dicarboxylic acids on a fused silica capillary column, J. Chromatogr. 301 (1984) 273-276.

[27] M. Zhang, F.L.P. Resende, A. Moutsoglou, Catalytic fast pyrolysis of aspen lignin via PyGC/MS, Fuel 116 (2014) 358-369.

[28] P.R. Patwardhan, R.C. Brown, B.H. Shanks, Product distribution from the fast pyrolysis of hemicellulose, ChemSusChem. 4 (2011) 636-43.

[29] P.R. Patwardhan, J.A. Satrio, R.C. Brown, B.H. Shanks, Product distribution from fast pyrolysis of glucose-based carbohydrates, J. Anal. Appl. Pyrolysis 86 (2009) 323-330.

[30] P.R. Patwardhan, R.C. Brown, B.H. Shanks, Understanding the fast pyrolysis of lignin, ChemSusChem. 4 (2011) 1629-1636.

[31] SW-846 Test Method 8000C, Section 11.5.1: Volatile Organic Compounds by Gas Chromatography/Mass Spectrometry (GC/MS).

[32] A.V. Bridgwater, D. Meier, D. Radlein, An overview of fast pyrolysis of biomass, Org. Chem. 30 (1999) 1479-1493. 
a)

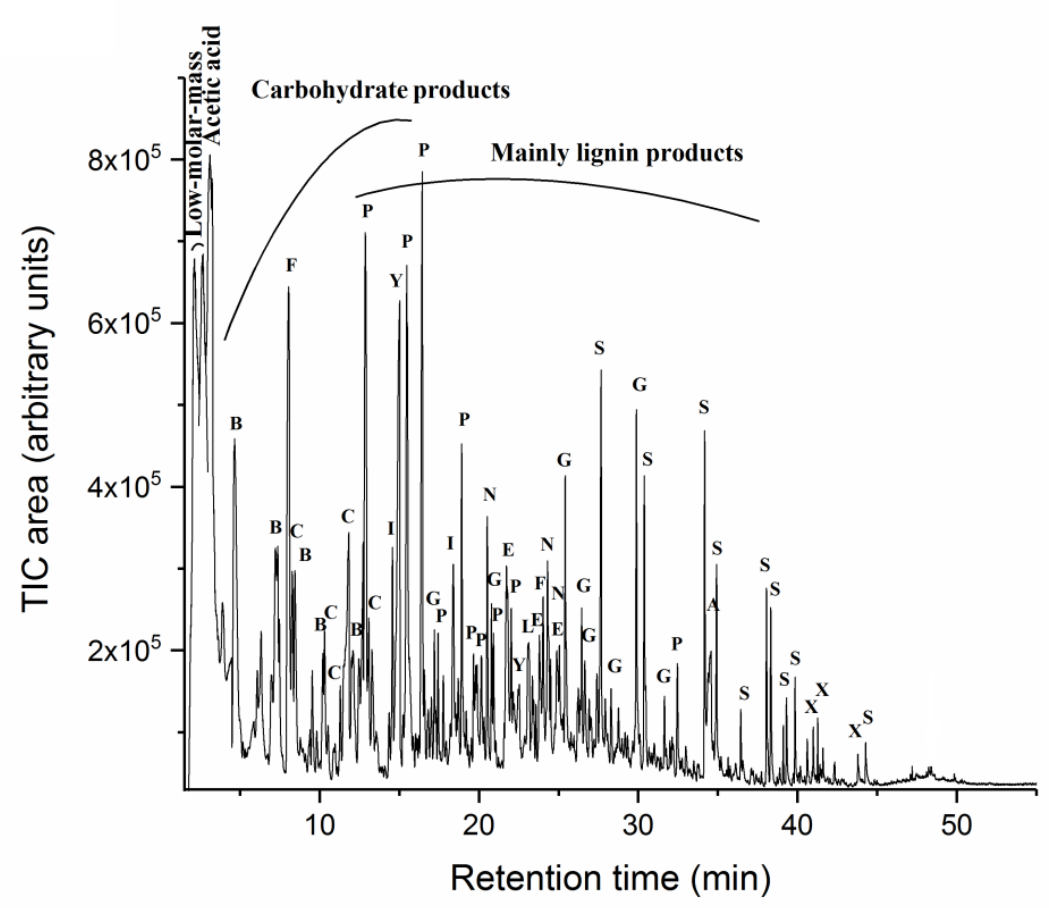

b)

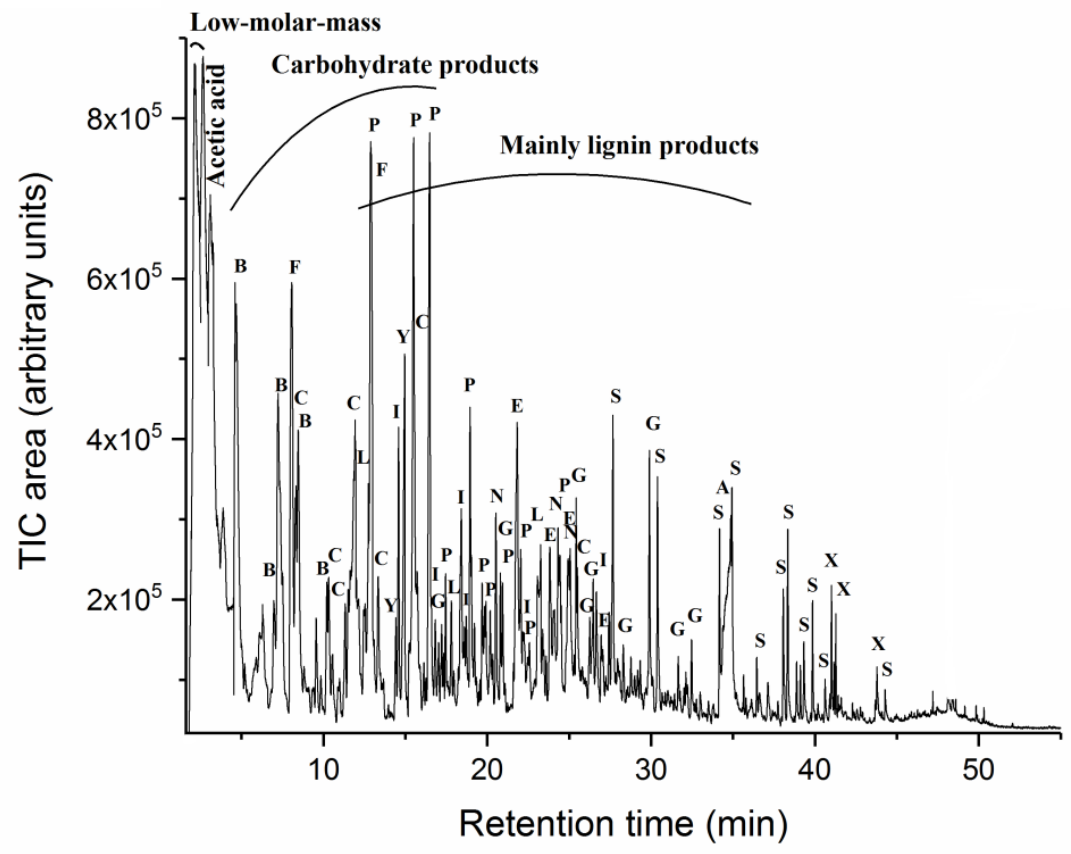

Fig. 1. The main products formed in the pyrolysis experiments $\left(700{ }^{\circ} \mathrm{C}\right.$ and $\left.20 \mathrm{~s}\right)$ with untreated (a) and hot-water-extracted (b) birch sawdust. Letters indicate compound groups to which identified products belong: A (anhydrosugar derivatives), B (benzene derivatives), C (cyclopentenone derivatives), $\mathrm{E}$ (catechol and benzenediol derivatives), $\mathrm{F}$ (furan derivatives), $\mathrm{G}$ 
(guaiacol derivatives), I (indene derivatives), L (lactone derivatives), $\mathrm{N}$ (naphthalene derivatives), $\mathrm{P}$ (phenol derivatives), $\mathrm{S}$ (syringol derivatives), $\mathrm{X}$ (fatty acids derivatives), and $\mathrm{Y}$ (pyrone derivatives).

a)

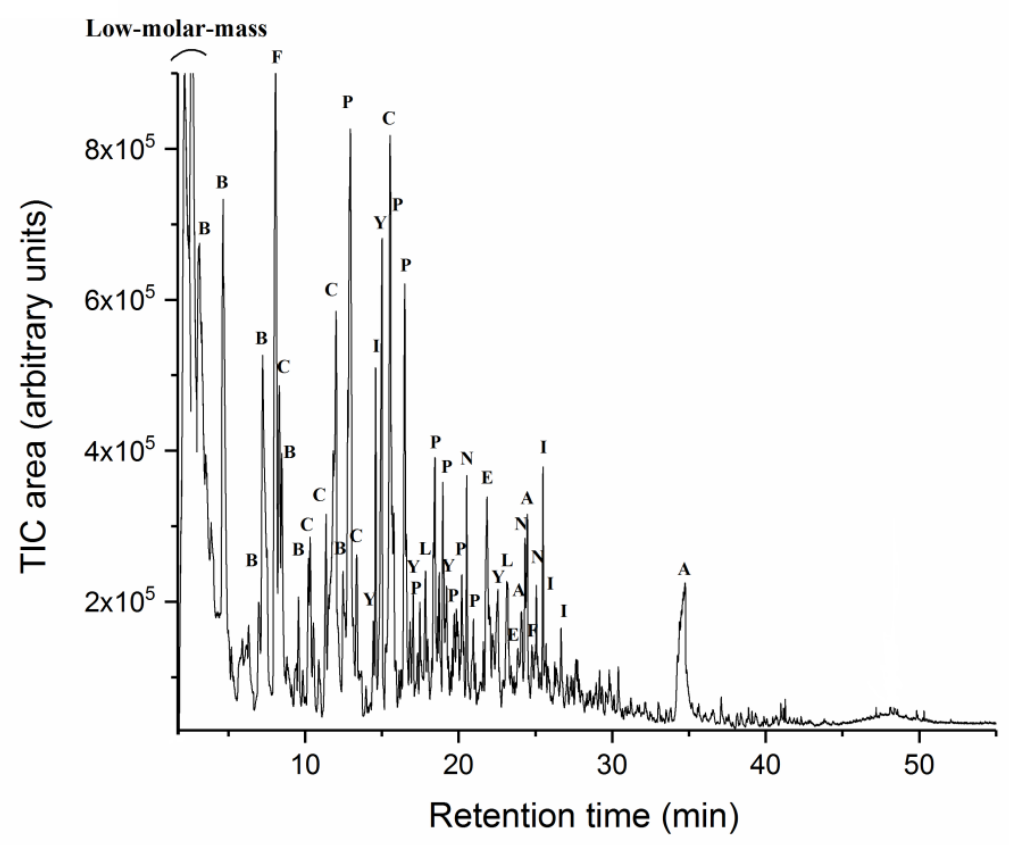

b)

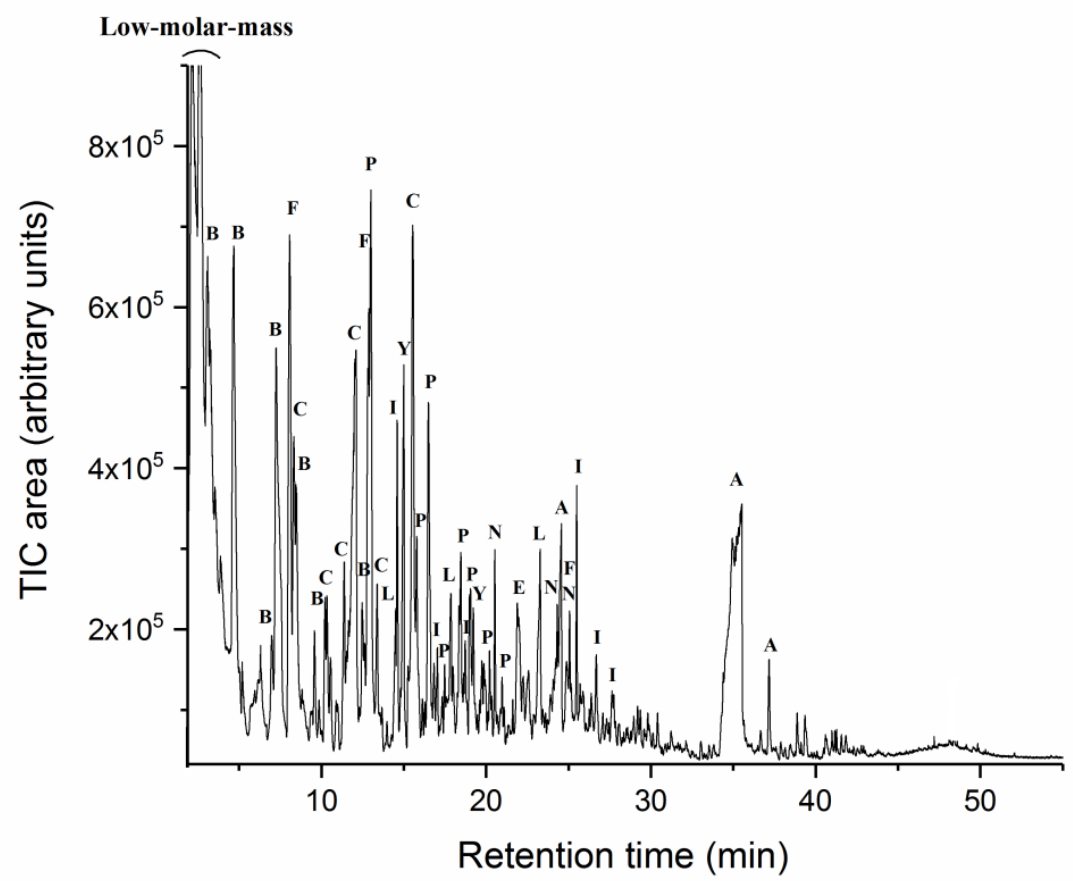


Fig. 2. The main products formed in the pyrolysis experiments $\left(700^{\circ} \mathrm{C}\right.$ and $\left.20 \mathrm{~s}\right)$ with soda-AQdelignified pulps of untreated (a) and of hot-water-extracted (b) birch sawdust. For the letter symbols, see Fig. 1.

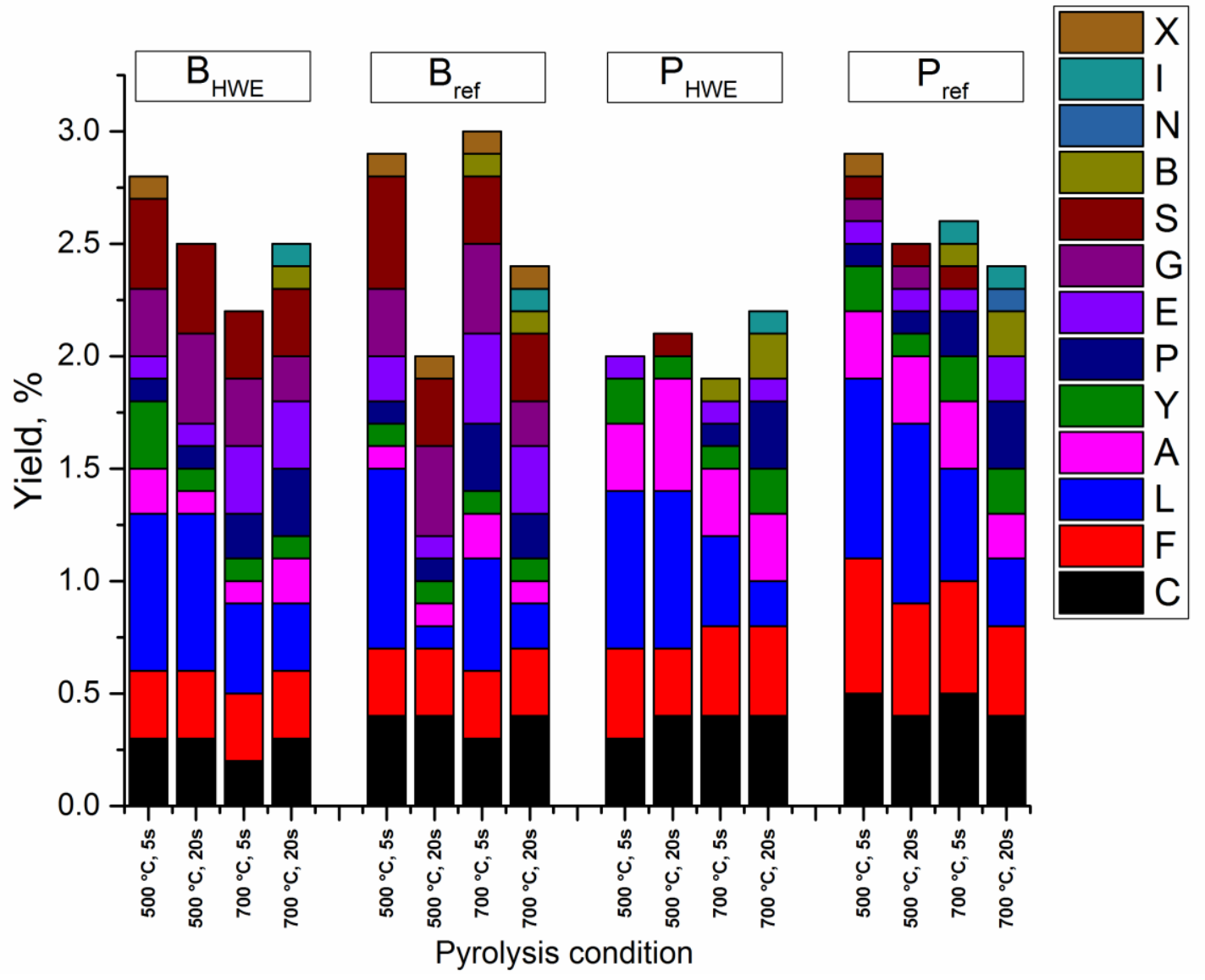

Fig. 3. Effect of pyrolysis temperature and residence time on yields of various product groups. For the letter symbols, see Fig. 1. 


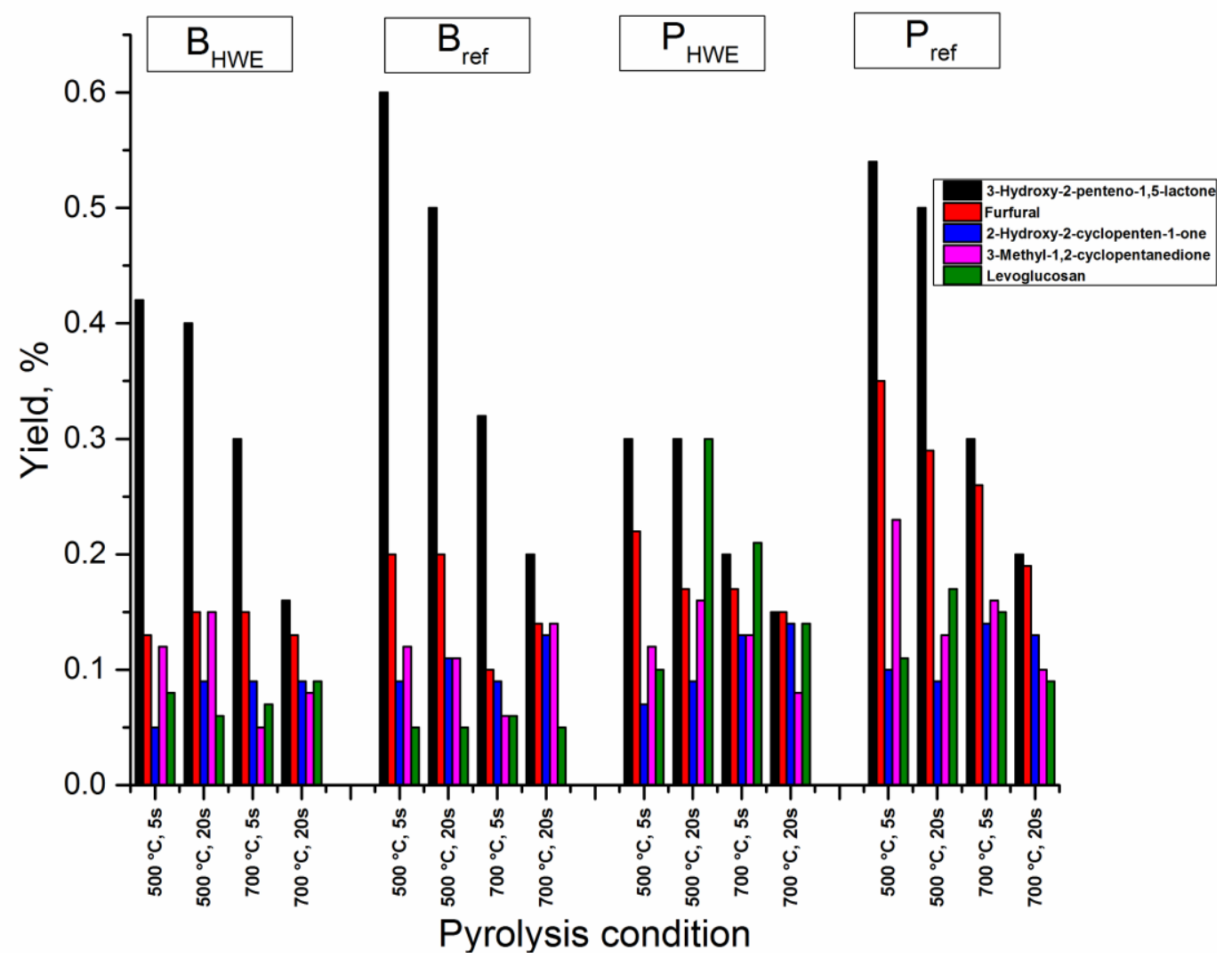

Fig. 4. Effects of pyrolysis temperature and residue time on yields of prominent pyrolysis products. 


\section{Table 1}

Chemical composition of the initial and differently-treated birch sawdust (\% of the sample ${ }^{\text {a }}$ dry solids)

\begin{tabular}{|c|c|c|c|c|}
\hline Components & $\mathrm{B}_{\text {HWE }}$ & $\mathrm{B}_{\text {ref }}$ & $P_{\text {HWE }}$ & $\mathrm{P}_{\text {ref }}$ \\
\hline Carbohydrates & 72.7 & 67.5 & 88.7 & 91.5 \\
\hline Arabinose & 0.1 & 0.4 & - & - \\
\hline Galactose & 0.6 & 1.0 & 1.0 & 0.8 \\
\hline Glucose & 60.8 & 43.4 & 80.6 & 66.8 \\
\hline Mannose & 1.0 & 1.4 & 0.3 & 0.4 \\
\hline Xylose & 10.2 & 21.3 & 6.8 & 23.5 \\
\hline Lignin & 20.7 & 22.1 & 0.8 & 2.1 \\
\hline Klason & 18.2 & 17.6 & 0.2 & 1.2 \\
\hline Acid-soluble & 2.5 & 4.5 & 0.6 & 0.9 \\
\hline Extractives & 2.8 & 2.9 & 0.7 & 0.6 \\
\hline Others & 3.8 & 7.5 & 9.8 & 5.8 \\
\hline Total & 100.0 & 100.0 & 100.0 & 100.0 \\
\hline
\end{tabular}

\footnotetext{
${ }^{\mathrm{a}} \mathrm{B}_{\mathrm{HWE}}$ and $\mathrm{B}_{\text {ref }}$ refer to hot-water-extracted and untreated sawdust, respectively, and $\mathrm{P}_{\mathrm{HWE}}$ and $\mathrm{P}_{\text {ref }}$ refer to the soda-AQ-delignified pulps of hot-water-extracted and untreated sawdust, respectively.

${ }^{\mathrm{b}}$ Monosaccharide units are presented as their anhydro forms.
} 
Table 2

The main products formed in the pyrolysis experiments with differently-treated birch sawdust

\begin{tabular}{|c|c|c|}
\hline Product & $\begin{array}{l}\text { Retention time } \\
(\min )\end{array}$ & $\begin{array}{l}\text { Group } \\
\text { symbol }\end{array}$ \\
\hline Anhydrosugars & & $\mathrm{A}$ \\
\hline 1,4:3,6-Dianhydro- $\alpha$-D-glucopyranose & 24.0 & \\
\hline 1,6-Anhydro- $\beta$-D-glucopyranose (levoglucosan) * & 34.5 & \\
\hline Benzene derivatives & & $\mathrm{B}$ \\
\hline Toluene $*$ & 4.6 & \\
\hline$o$-Xylene $*$ & 7.3 & \\
\hline Cyclopentenone derivatives & & $\mathrm{C}$ \\
\hline Cyclopent-2-en-1-one $*$ & 8.3 & \\
\hline 2-Methylcyclopent-2-en-1-one * & 10.3 & \\
\hline 2-Cyclopenten-1,4-dione & 11.2 & \\
\hline 2-Hydroxycyclopent-2-en-1-one & 11.8 & \\
\hline 3-Methyl-1,2-cyclopentanedione * & 15.4 & \\
\hline Catechol derivatives & & $\mathrm{E}$ \\
\hline 1,2-Dihydroxybenzene (catechol) * & 21.7 & \\
\hline 1,2-Dihydroxy-3-methylbenzene * & 23.7 & \\
\hline 1,2-Dihydroxy-3-methoxybenzene * & 24.3 & \\
\hline 1,2-Dihydroxy-4-methylbenzene & 24.8 & \\
\hline 1,4-Dihydroxy-2,5-dimethylbenzene & 26.9 & \\
\hline Furan derivatives & & $\mathrm{F}$ \\
\hline Furfural (furan-2-carbaldehyde) * & 8.0 & \\
\hline 5-Methylfurfural * & 12.8 & \\
\hline 2,5-Furandicarboxaldehyde $*$ & 19.1 & \\
\hline 5-(Hydroxymethyl)furfural * & 24.7 & \\
\hline Guaiacol derivatives & & $\mathrm{G}$ \\
\hline 2-Methoxyphenol (guaiacol) * & 17.2 & \\
\hline 2-Methoxy-4-methylphenol * & 20.7 & \\
\hline 4-Ethenyl-2-methoxyphenol & 25.4 & \\
\hline 2-Methoxy-4-(prop-2-en-1-yl)phenol (eugenol) * & 26.4 & \\
\hline 2-Methoxy-4-(prop-1-en-1-yl)phenol (isoeugenol) * & 28.3 & \\
\hline Indene derivatives & & I \\
\hline $1 H$-Indene $*$ & 14.6 & \\
\hline 1-Methyl-1H-indene & 18.4 & \\
\hline 2,3-Dihydro-1H-inden-1-one & 25.6 & \\
\hline Lactone derivatives & & $\mathrm{L}$ \\
\hline 5H-Furan-2-one & 12.7 & \\
\hline 3-Hydroxy-2-penteno-1,5-lactone & 15.0 & \\
\hline 4-hydroxy-2,5-dimethylfuran-3-one * & 17.8 & \\
\hline 1-Hydroxy-3,6-dioxabicyclo[3-2.1]octan-2-one & 23.2 & \\
\hline Naphthalene derivatives & & $\mathrm{N}$ \\
\hline Naphthalene $*$ & 20.5 & \\
\hline
\end{tabular}


1-Methylnaphthalene

Phenol derivatives

Phenol *

12.9

2-Methylphenol *

4-Methylphenol *

16.4

2,4-Dimethylphenol

18.9

3,5-Dimethylphenol *

19.7

4-(Prop-2-en-1-yl)phenol

24.5

Syringol derivatives

2,6-Dimethoxyphenol (syringol) *

4-Allyl-4-methyl-2,6-dimethoxyphenol

27.6

1-(4-Hydroxy-3-methoxyphenyl)ethan-1-one *

30.3

4-Ethenyl-2,6-dimethoxyphenol

32.4

4-Allyl-2,6-dimethoxyphenol (4-allylsyringol) *

34.1

4-Hydroxy-3,5-dimethoxybenzaldehyde

34.9

1-(4-Hydroxy-3,5-dimethoxyphenyl)ethanal

38.3

4'-Hydroxy-3',5'-dimethoxyacetophenone *

39.3

3-(4-Hydroxy-3,5-dimethoxyphenyl)prop-2-enal

39.8

44.3

Pyrone derivatives

Pyran-2-one

14.5

3-Hydroxy-2-methylpyran-4-one *

19.3

3,4-Dihydro-6-methyl-2H-pyran-2-one

22.4

Fatty acid derivatives

Hexadecanoic acid

9,12-Octadecadienoic acid

43.8

$\mathrm{P}$

S

*Confirmed by the pure standards.

\section{Table 3}

Percentage ratio aliphatic compounds/aromatic compound in pyrolysates (for abbreviations, see Table 1)

\begin{tabular}{lllll}
\hline Condition & $\mathrm{B}_{\text {HWE }}$ & $\mathrm{B}_{\text {ref }}$ & $\mathrm{P}_{\text {HWE }}$ & $\mathrm{P}_{\text {ref }}$ \\
\hline $500{ }^{\circ} \mathrm{C} / 5 \mathrm{~s}$ & $67 / 33$ & $63 / 37$ & $95 / 5$ & $87 / 13$ \\
$500{ }^{\circ} \mathrm{C} / 20 \mathrm{~s}$ & $62 / 38$ & $65 / 35$ & $95 / 5$ & $84 / 16$ \\
$700{ }^{\circ} \mathrm{C} / 5 \mathrm{~s}$ & $52 / 48$ & $50 / 50$ & $89 / 11$ & $81 / 19$ \\
$700{ }^{\circ} \mathrm{C} / 20 \mathrm{~s}$ & $50 / 50$ & $56 / 44$ & $73 / 27$ & $71 / 29$ \\
\hline
\end{tabular}

